Article

\title{
Insights into Indoor/Outdoor PM Concentration Ratios due to Dust Storms in an Arid Region
}

\section{Helena Krasnov ${ }^{1, *}$, Itzhak Katra ${ }^{1}$ and Michael D. Friger ${ }^{2}$}

1 Department of Geography and Environmental Development, Ben-Gurion University of the Negev, Beer-Sheva 84105, Israel; E-Mail: katra@bgu.ac.il

2 Department of Public Health, Faculty of Health Sciences, Ben-Gurion University of the Negev, Beer-Sheva 84105, Israel; E-Mail: friger@bgu.ac.il

* Author to whom correspondence should be addressed; E-Mail: krasnovh@ post.bgu.ac.il; Tel.: +972-8642-8948; Fax: +972-8647-2821.

Academic Editor: Pasquale Avino

Received: 13 May 2015 / Accepted: 17 June 2015 / Published: 25 June 2015

\begin{abstract}
Dust storms have impacts on both human and physical environments, associated with an increase in atmospheric particulate matter (PM) concentrations. Most studies on exposure to PM have focused on the outdoor air, while information on indoor pollution, is still lacking. The aim of this study was to examine the impact of desert dust events on PM concentrations in indoor environments. A total of over 200 real time measurements of PM were conducted in houses in the Negev Desert during dust storms. Indoor and outdoor PM concentrations were characterized, as well as the relationships between the two datasets. The findings indicated that atmospheric $\mathrm{PM}_{10}$ concentrations can increase from $20-120 \mu \mathrm{g} \cdot \mathrm{m}^{-3}$ on non-dust days to more than $1500 \mu \mathrm{g} \cdot \mathrm{m}^{-3}$ during dust events. Indoor concentrations can reach as high as $1000 \mu \mathrm{g} \cdot \mathrm{m}^{-3}$. The calculated indoor/outdoor (I/O) PM ratio ranged from 0.79 for low-level storms to 0.58 during stronger events. Indoor PM concentrations were found to be dependent on the dust storm intensity (low, medium, high) and duration with a time lag. The information obtained in this study is critical for assessment of policy interventions to reduce exposure risk and health effects due dust storms.
\end{abstract}

Keywords: PM; indoor; outdoor; dust storms; spatial distribution; arid areas 


\section{Introduction}

Desert dust storms are a natural phenomenon which can pose a serious environmental hazard. The origin of the dust is mainly from desert soils and it contains diverse mineral and organic components [1]. During dust events, which can last for several days, $\mathrm{PM}_{10}$ concentrations (particulate matter with aerodynamic diameter less than $10 \mu \mathrm{m}$ ) increase far beyond air quality guidelines [2-4].

A number of epidemiological studies have associated risk exposure to ambient PM10 levels during desert dust outbreaks with increased cardiovascular and respiratory hospital admissions or even mortality [5-7]. A study by Perez et al. showed that an increase of $10 \mu \mathrm{g} \cdot \mathrm{m}^{-3}$ of PM during Sahara dust storms was associated with an increase in all-cause daily mortality of 8.4\% [8]. A 10-year analysis of respiratory and cardiovascular morbidity in Nicosia, Cyprus showed that cardiovascular admissions were $10.4 \%$ higher during dust days [9]. The majority of epidemiological studies however were performed in non-arid urban environments. In addition these studies are based on outdoor PM measurements, although people are also exposed to PM in indoor environments such as homes, schools, offices and restaurants, where they spend most of their time- in particular during dust events.

Atmospheric PM has already been recognized as a matter of significant concern related to indoor air quality [10-13]. Understanding of how indoor exposure relates to outdoor concentrations is critical for assessment of policy interventions to reduce adverse health effects. However, the relations between outdoor and indoor PM concentrations during natural dust events remain unclear. Arid and semi-arid regions are strongly associated with dust storms due to their proximity to dust sources [14]. Hundreds of millions of people live in such regions throughout the world (mainly in Africa and Asia) and therefore are exposed to increased atmospheric PM due to dust storms.

This study explores variations in outdoor and indoor PM levels in an arid city (Beer Sheva) through analyses of real-time data collected during a series of dust events. The city of Beer Sheva (Negev, Israel) is located at the margins of the global dust belt, which extends between West Africa and Saudi Arabia, and is frequently subjected to elevated PM concentrations due to dust storms $[15,4]$. This study aims to provide a better understanding of the natural dust phenomenon and to support decision making on environmental and health issues.

\section{Methods}

Dust storms in the Beer Sheva region occur mostly during the winter, associated with a passage of cold fronts followed by relatively high wind speeds $(>6 \mathrm{~m} / \mathrm{s})$. The spring and the autumn seasons are characterized by mild storms while the summer is considered a dust-free season. A long-term analysis of atmospheric (outdoor) $\mathrm{PM}_{10}$ concentrations in the studied region [4] showed that dust storms can contribute a daily average PM concentration of up to $2643 \mu \mathrm{g} \cdot \mathrm{m}^{-3}$, while the average background value for non-dust days is $42 \mu \mathrm{g} \cdot \mathrm{m}^{-3}$. Hourly levels of $\mathrm{PM}_{10}$ concentrations can reach as much as $5000 \mu \mathrm{g} \cdot \mathrm{m}^{-3}$.

The data set was comprised of measurements collected during both dust and non-dust days (background) during August 2013-March 2015. Measurements for this study were conducted during 18 dust storms. In each dust storm 5 to 15 houses were measured, depending on the event duration (from $2-3 \mathrm{~h}$ to 2 days). Overall 210 houses were sampled, in which 210 and 175 measurements 
(outdoor and indoor $\mathrm{PM}_{10}$ ) were conducted during non-dust and dust days respectively. Seven houses were visited a number of times during different dust events. The measurements were performed with portable real-time dust monitoring devices (TSI DustTrak DRX 8534; detection range 1 to $100,000 \mu \mathrm{g} \cdot \mathrm{m}^{-3}$, reading resolution of $0.001 \mathrm{mg} \cdot \mathrm{m}^{-3}$, accuracy of $\left.1 \%\right)$. PM10 concentrations were recorded at 5-s intervals. In the indoor environment, the device was operated in the living room while all windows and doors were closed and air conditioning, cooking or smoking were not allowed. The corresponding outdoor measurements were recorded from a balcony or backyard of each house.

The PM database was assembled thanks to the use of portable monitoring devices (TSI DustTrak). The TSI DustTrak has gained widespread use in numerous studies of indoor and outdoor PM $_{2.5}$ and $\mathrm{PM}_{10}$ due to its sensitivity to a range of different aerosols, fast response time, and high temporal measurement resolution. Natural dust particles are very similar to the Arizona Dust used to calibrate the DustTrak (TSI, 1997), providing confidence for attaining a reasonable measurement of the PM concentration during dust events [16]. Data from the DustTrak can be corrected for more accurate mass concentrations [17-22]. In this study, the procedure of the real-time measurements included preliminary tests of the DustTrak readings through comparisons with records from a standard environmental PM monitor (Thermo Scientific TEOM ${ }^{\circledR}$ 1405-DF) located in the center of Beer Sheva, which operates within the framework of the national air monitoring system.

\section{Results and Discussion}

Figure 1 shows the $\mathrm{PM}_{10}$ mean concentrations in indoor and outdoor environments during the non-dust days (background). The different colors represent the PM levels from lowest (cold colors) to highest (warm colors) concentrations divided to five groups. Outdoor concentrations range between 24-120 $\mu \mathrm{g} \cdot \mathrm{m}^{-3}$. The larger group (56\%) was within the range of $43-71 \mu \mathrm{g} \cdot \mathrm{m}^{-3}$ (light green). PM concentrations above $86 \mu \mathrm{g} \cdot \mathrm{m}^{-3}$ (orange) were found for a small group of 24 houses (11\%) while concentrations above $103 \mu \mathrm{g} \cdot \mathrm{m}^{-3}$ were found only for $6 \%$. Since the point measurements were performed from August 2013 to March 2015, the range can be related to temporal variations in which PM can be somewhat higher during the day time compared to evening, and during summer compared to the winter. The overall range of the PM concentrations on non-dust days is typical for Beer Sheva area based on long term analysis [4]. However the PM concentrations on non-dust days are significantly lower than those of dust events.

The indoor concentrations ranged between 20 to $492 \mu \mathrm{g} \cdot \mathrm{m}^{-3}$. The lowest concentrations $\left(20-42 \mu \mathrm{g} \cdot \mathrm{m}^{-3}\right)$ were recorded in $6 \%$ of the houses (blue dots). The larger portion of houses (38\%) was in the range of $103-492 \mu \mathrm{g} \cdot \mathrm{m}^{-3}$ (red color). The higher PM concentrations (above $103 \mu \mathrm{g} \cdot \mathrm{m}^{-3}$ ) in the indoor environment can be related mainly to the house characteristics.

The correlations coefficient between the indoor and outdoor $\mathrm{PM}_{10}$ was calculated (Figure 2). During the background period, the correlation coefficient was relatively weak $-48 \%$ ( $\mathrm{sig}<0.001)$, indicating that the house conditions are a more dominant effector on the indoor PM concentrations. However during elevated PM concentrations following dust storms the $\mathrm{PM}_{10}$ concentrations increased significantly above the background values (up to $2300 \mu \mathrm{g} \cdot \mathrm{m}^{-3}$ ). The correlation coefficient during dust events increased to $79 \%$ ( $\mathrm{sig}<0.001$ ). This is related to the atmospheric (outdoor) PM as a major controlling factor on indoor PM during dust events. 

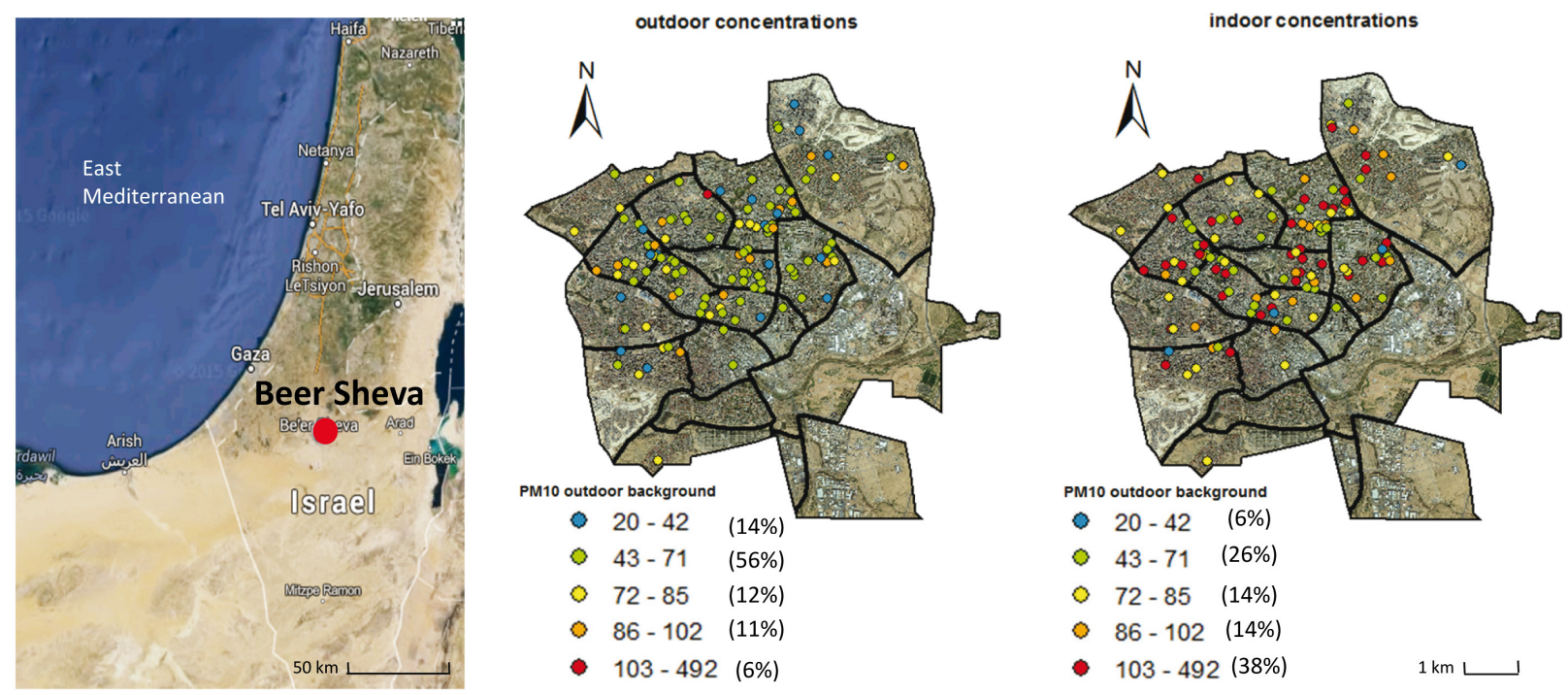

Figure 1. Measurement locations of outdoor (left) and indoor (right) $\mathrm{PM}_{10}$ concentrations during background (non-dust days) in Beer Sheva. The different dot colors represent the PM levels from lowest (cold colors) to highest (warm colors) concentrations. Concentrations are given in $\mu \mathrm{g} \cdot \mathrm{m}^{-3}$. Percentages in brackets indicate the relative fraction of houses within the indicated particulate matter (PM) concentration range.
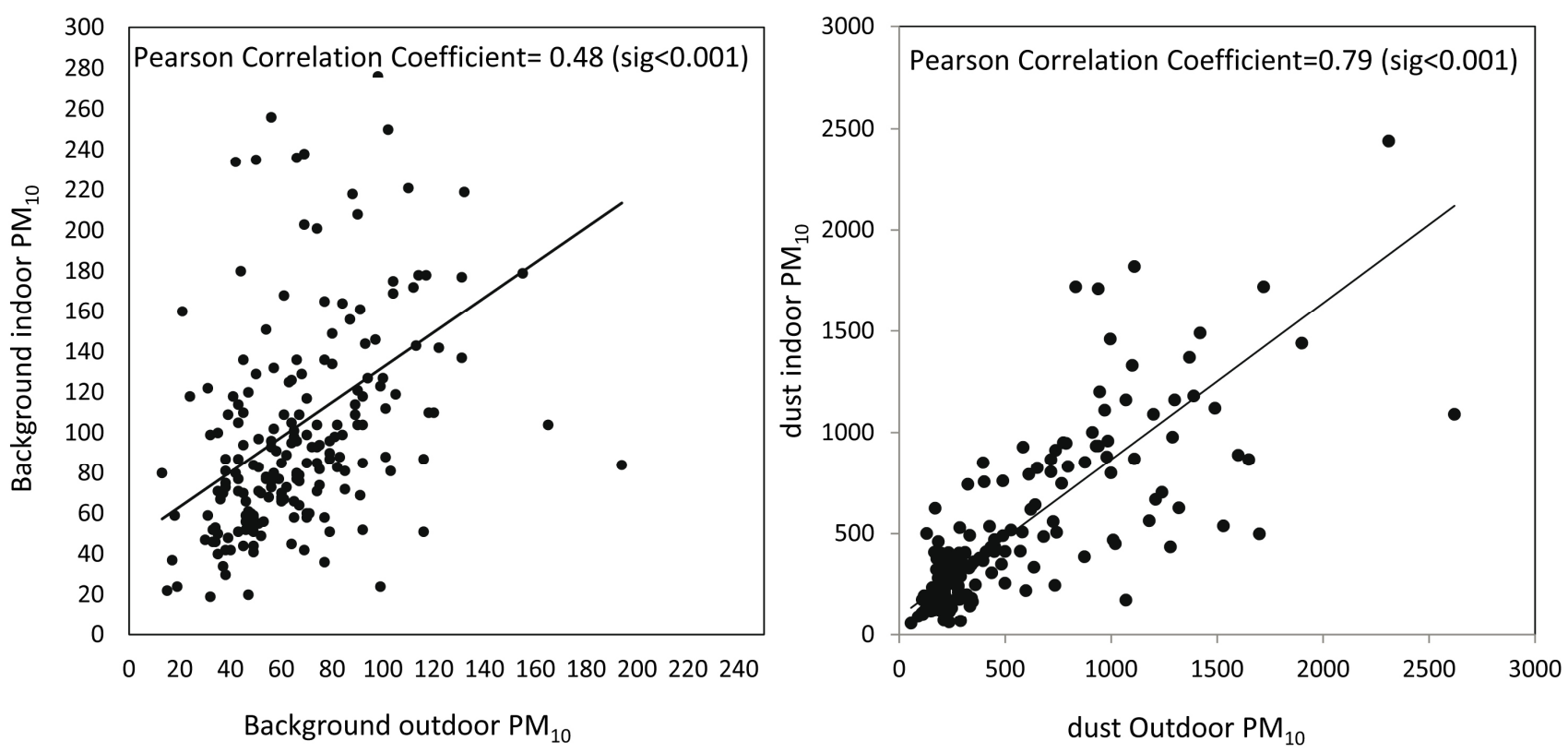

Figure 2. Correlation factors between outdoor and indoor $\mathrm{PM}_{10}$ concentrations during background (non- dust days, left) and dust events (right). Note the difference in the scale of Y axis.

In order to examine the PM concentrations over time during dust events, continuous $\mathrm{PM}_{10}$ measurements in the indoor and outdoor environments in typical houses in the study area were performed. In the example presented in Figure 3, it is shown that during non-dust days (measured over several days - see methods chapter), the indoor $\mathrm{PM}_{10}$ concentrations vary from 20 to $118 \mu \mathrm{g} \cdot \mathrm{m}^{-3}$ 
(44 $\mu \mathrm{g} \cdot \mathrm{m}^{-3}$ on average). The corresponding outdoor concentrations (measured outside the house) were within a similar range of $20-110 \mu \mathrm{g} \cdot \mathrm{m}^{-3}$. The correlation between the indoor and outdoor PM measurements was relatively high, $87 \%$ ( $\operatorname{sig}<0.001)$.

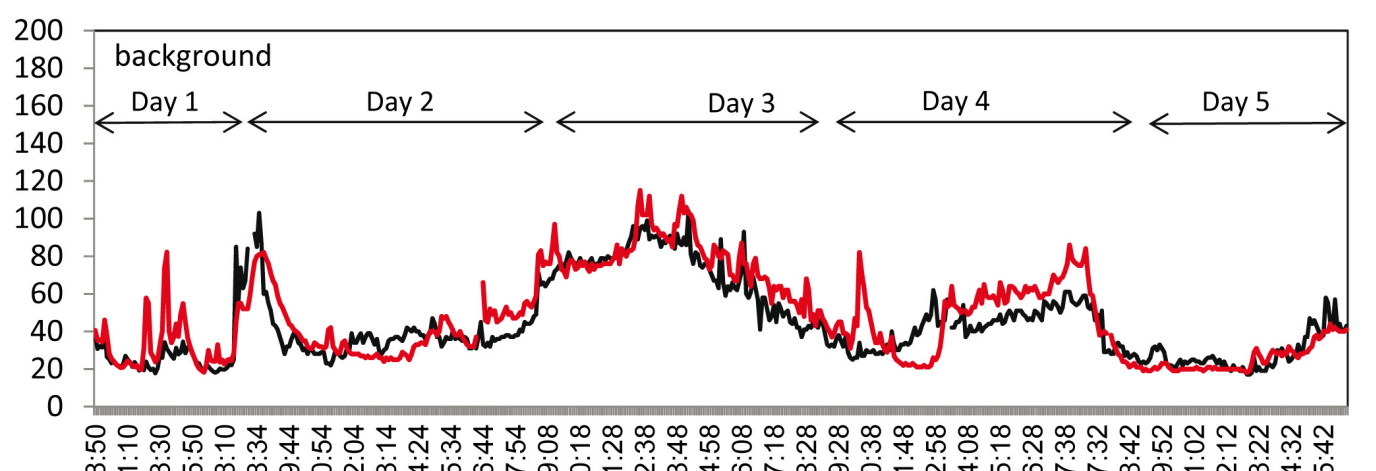

o̊
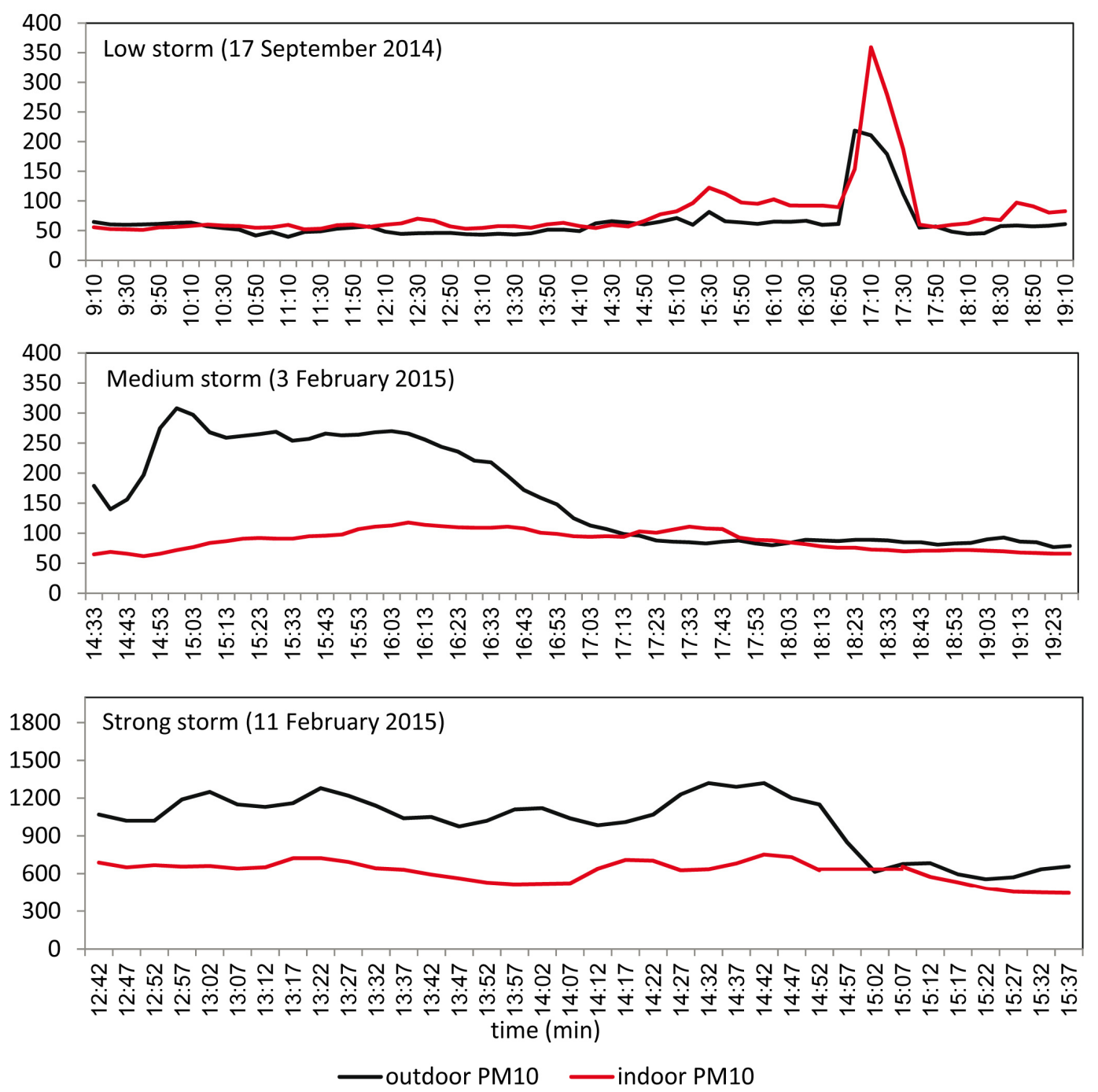

Figure 3. $\mathrm{PM}_{10}$ concentrations in a typical house during background (upper graph) and different dust event levels (low, medium, high). The background measurements were collected during several days. Note the differences in $\mathrm{Y}$ axis scales. 
Figure 3 also shows the indoor and outdoor concentrations during dust storms with different intensities. The low intensity dust storms of September 2014 reached atmospheric (outdoor) concentrations of $220 \mu \mathrm{g} \cdot \mathrm{m}^{-3}$ after an initial background value of about $50 \mu \mathrm{g} \cdot \mathrm{m}^{-3}$. The dust event lasted for about an hour before the background value was reduced again to the level of $50 \mu \mathrm{g} \cdot \mathrm{m}^{-3}$. The corresponding indoor concentrations during the background were slightly higher than those of the outdoor and reached $360 \mu \mathrm{g} \cdot \mathrm{m}^{-3}$ during the dust event itself (correlation $86 \%$, sig $<0.001$ ). The increase in the indoor concentration occurred $10 \mathrm{~min}$ after the beginning of the dust event, and decreased to the background values about $30 \mathrm{~min}$ after the end of the event.

The medium intensity dust storm of 3 February 2015 lasted $3 \mathrm{~h}$ and atmospheric concentrations exceeded $300 \mu \mathrm{g} \cdot \mathrm{m}^{-3}$. After $3 \mathrm{~h}$, the concentrations dropped to a value of $80 \mu \mathrm{g} \cdot \mathrm{m}^{-3}$, which is above the normal background values. The corresponding indoor concentrations rose from $65 \mu \mathrm{g} \cdot \mathrm{m}^{-3}$ to $118 \mu \mathrm{g} \cdot \mathrm{m}^{-3}$ (correlation 34\%, sig $<0.001$ ). The higher indoor concentrations persisted for about $2 \mathrm{~h}$ after outdoor concentrations began to decrease. The strong dust storm of 11 February 2015 was characterized by high outdoor and indoor levels $\left(1320 \mu \mathrm{g} \cdot \mathrm{m}^{-3}\right.$ and $750 \mu \mathrm{g} \cdot \mathrm{m}^{-3}$ respectively), lasting for more than $3 \mathrm{~h}$. The indoor concentrations increased by 17 fold from the average indoor background (correlation $70 \%$, sig $<0.001$ ). After $3 \mathrm{~h}$ the outdoor concentrations decreased to $600 \mu \mathrm{g} \cdot \mathrm{m}^{-3}$. The indoor concentrations, however, remained at their highest level throughout the entire measurement period.

During non-dust days the indoor concentrations is somewhat higher than the corresponding outdoor concentrations due to low air exchange in houses compared with the outside. The trend remains during low storms and follows the small increase in outdoor concentrations. The outdoor concentrations reach extremely high values during medium to strong events. Probably only part of the particles penetrates into the indoor space, thus the trend is opposite to low storms with higher outdoor concentrations compared with indoor concentrations. Cross-correlation functions revealed a time lag for the increased indoor concentrations. The time lag is in the range of $10 \mathrm{~min}$ (one lag) to one hour (12 lag) (Figure 4).

This demonstrates the impact of dust storms on indoor PM concentrations. The increase in indoor concentrations occurs even during a low-intensity dust storm in the area, with a short-term response during the peak of the dust storm. In the stronger storms, the indoor concentrations increase to high levels in terms of air quality and remain high for a long period of time. Typically, stronger storms are associated with stronger wind speeds, which can increase the pressure on windows and doors of houses and thus the penetration rates of particles from outdoor to indoor. However the high PM concentrations in the indoor environment following dust event persist for a long time.

Calculation of the indoor and outdoor ratio (I/O ratio) directly represents the relationship between these concentrations. A number of studies found that $\mathrm{I} / \mathrm{O}$ ratios vary within in a wide range [11]. A study in Beijing demonstrated $\mathrm{I} / \mathrm{O}$ values between 0.6-0.9 and correlated it to wind speed and relative humidity changes during fog and haze episodes [23]. In this study, the average indoor/outdoor (I/O) ratio was $1.7(\mathrm{~S} . \mathrm{D}=0.3$ ) for non-dust days (background) (based on Figure 1). On dust days, this ratio was found to be dependent on the dust event level (Figure 3). For the low intensity event (17 September 2014) the $\mathrm{I} / \mathrm{O}$ is 1.24 , for the medium intensity event ( 3 February 2015 ) $\mathrm{I} / \mathrm{O}=0.68$, and for the strong event (11 February 2015) $\mathrm{I} / \mathrm{O}=0.58$. The values below 1 of the medium and the strong events $(0.58-0.68)$ represent the changes in the indoor-outdoor relationships due to dust events. 


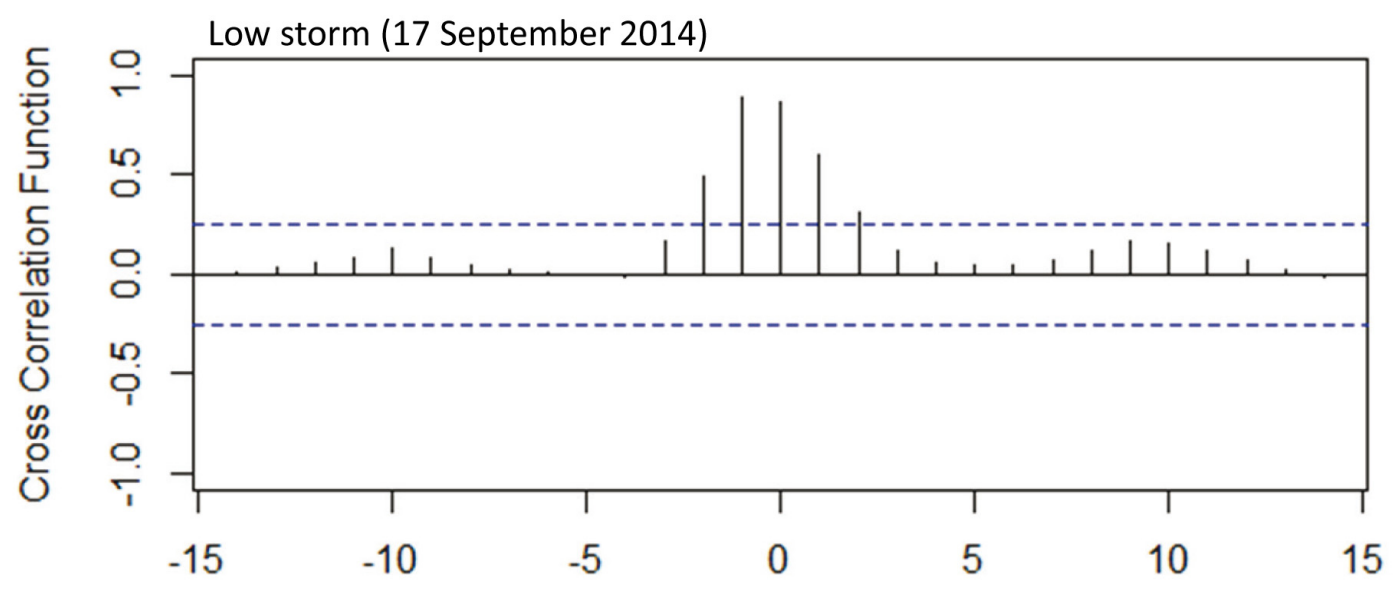

Lag

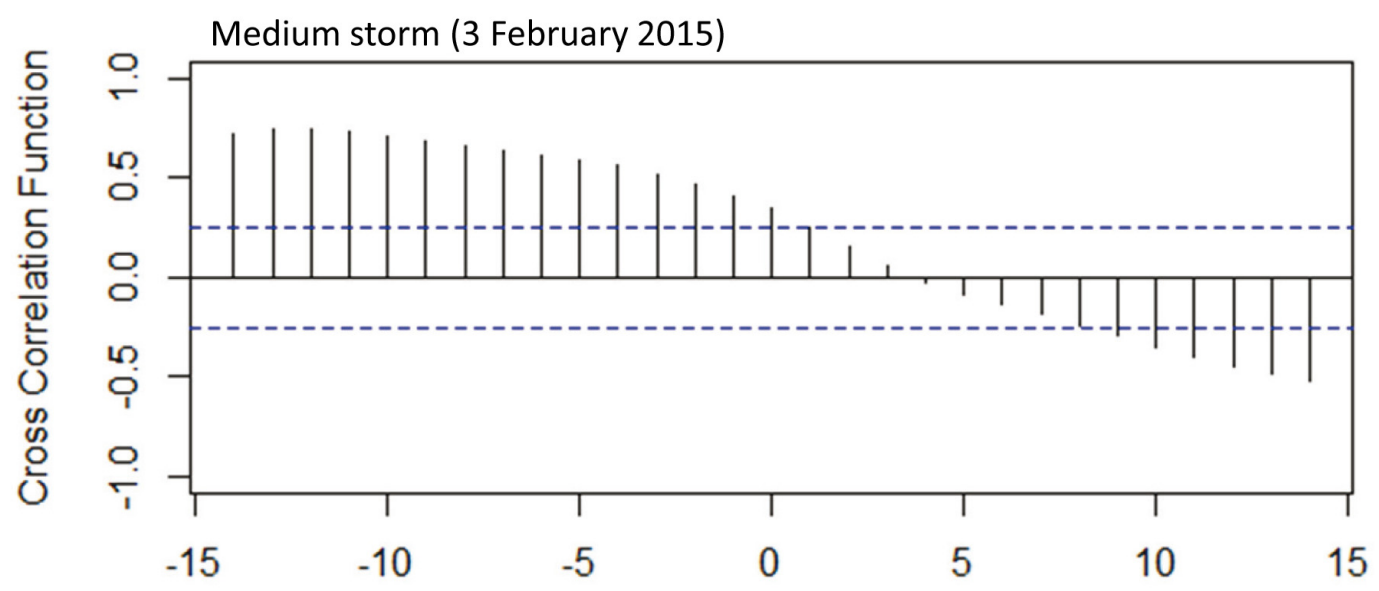

Lag

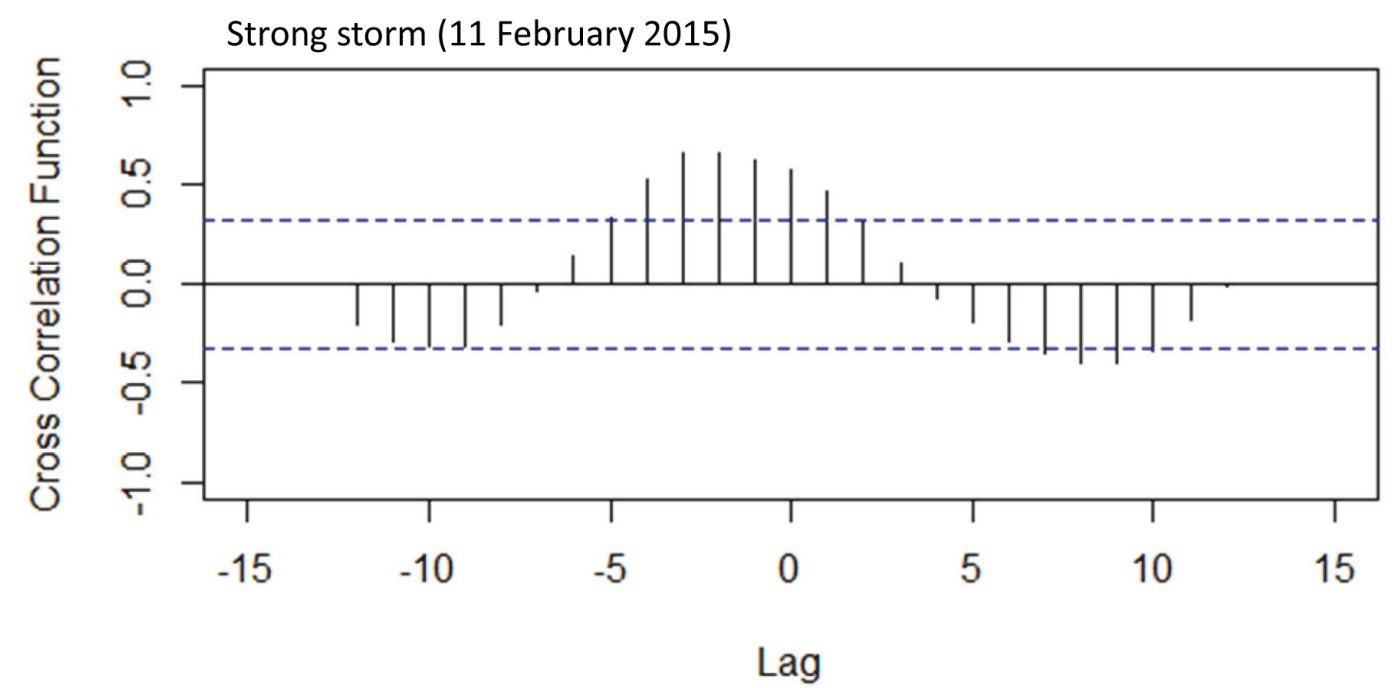

Figure 4. Cross correlation function between indoor and outdoor concentrations for the different storms. Correlation coefficient between outdoor and indoor PM measurements are (sig < 0.001): 86\% (17 September 2014); 43\% (3 February 2015); 70\% (11 February 2015). 
To further examine the indoor PM response to dust events, we compared the results of 7 houses during different dust events. The background levels recorded for indoor and outdoor environments of these houses are presented in Figure 5 along with the locations of the houses and the main wind direction (and dust sources) in the study area. Outdoor PM10 concentrations during non-dust days ranged between $32-80 \mu \mathrm{g} \cdot \mathrm{m}^{-3}$. The lowest outdoor concentration was observed in house \#5, which is located relatively far from the dust sources. The highest concentration was measured in house \#7. Indoor levels were within the range of $42-102 \mu \mathrm{g} \cdot \mathrm{m}^{-3}$. The lowest concentration was recorded in house \#5, while the highest was measured in houses \#3 and \#4.

The indoor and outdoor levels for the same houses during three winter dust storms (west wind trajectory) are presented in Figure 6. The dust event of 11 December 2012 lasted $10 \mathrm{~h}$ at a medium storm level with average outdoor concentrations of $335 \mu \mathrm{g} \cdot \mathrm{m}^{-3}$. The highest indoor value $\left(346 \mu \mathrm{g} \cdot \mathrm{m}^{-3}\right)$ was measured in house \#4, and the lowest $\left(147 \mu \mathrm{g} \cdot \mathrm{m}^{-3}\right)$ was found in house \#1. In this event, the indoor concentrations were lower than those of the outdoor in 4 out of 5 measured houses. The I/O ratio was less than $1(0.74)$.

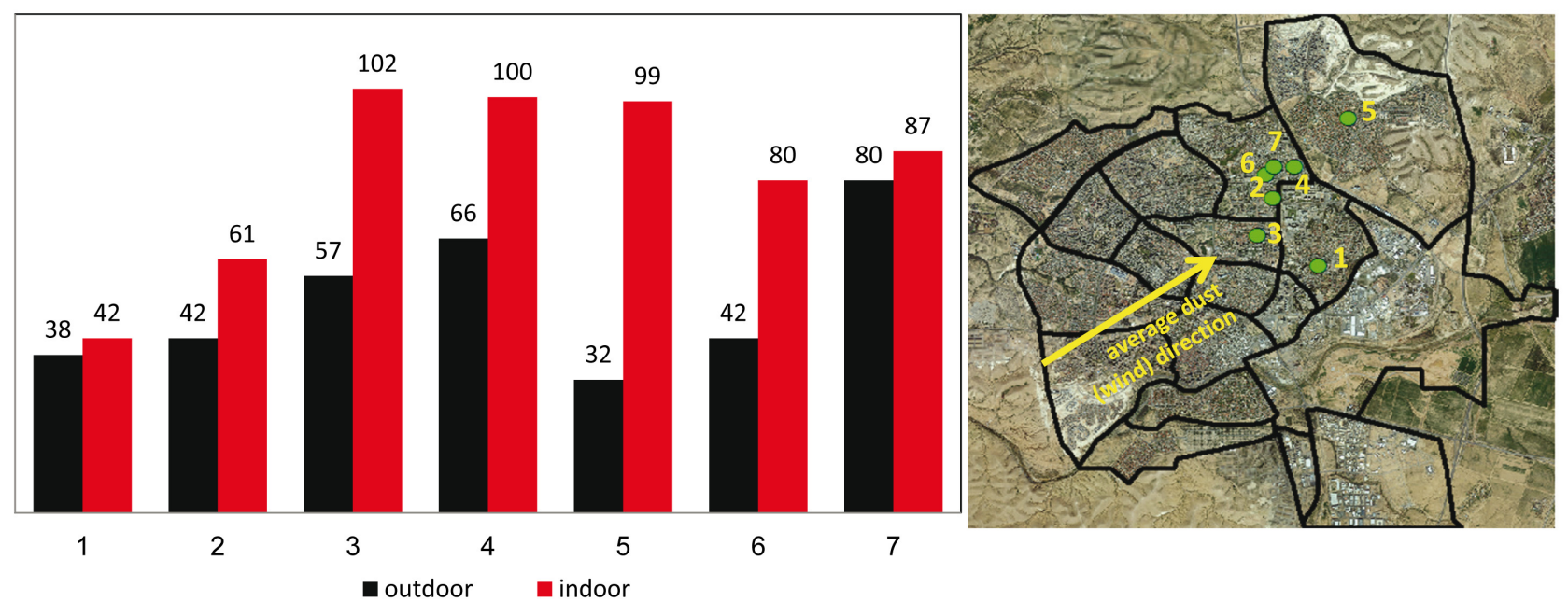

Figure 5. Example of outdoor and indoor $\mathrm{PM}_{10}$ concentrations (values in $\mu \mathrm{g} \cdot \mathrm{m}^{-3}$ are presented above the columns) in different houses during non-dust days. The locations of the houses are presented in the map (right panel) together with the main wind direction for the study region.

The dust events of 20 December 2012 and 6 January 2013 were high intensity storms. Both dust events lasted more than $10 \mathrm{~h}$. Average outdoor $\mathrm{PM}_{10}$ concentration for 20 December $2012 \mathrm{was} 1133 \mu \mathrm{g} \cdot \mathrm{m}^{-3}$ with a maximum hourly value of $1290 \mu \mathrm{g} \cdot \mathrm{m}^{-3}$. Very high outdoor and indoor concentrations were recorded in the five measured households. The highest outdoor level $\left(1020 \mu \mathrm{g} \cdot \mathrm{m}^{-3}\right)$ was found in house \#3; while house \#7 had the lowest level $\left(600 \mu \mathrm{g} \cdot \mathrm{m}^{-3}\right)$. In two of the houses $\# 1$ and \#3) the outdoor values were above $800 \mu \mathrm{g} \cdot \mathrm{m}^{-3}$ and higher than the corresponding indoor concentrations. The $\mathrm{I} / \mathrm{O}$ ratio was 0.79 on average.

During the storms of 6 January 2013, the $\mathrm{PM}_{10}$ concentrations reached a maximum value of $1956 \mu \mathrm{g} \cdot \mathrm{m}^{-3}$ (with an average value for the dust event of $561 \mu \mathrm{g} \cdot \mathrm{m}^{-3}$ ). The highest outdoor and indoor concentrations $\left(1000 \mu \mathrm{g} \cdot \mathrm{m}^{-3}\right.$ and $912 \mu \mathrm{g} \cdot \mathrm{m}^{-3}$ respectively) were found in house \#7, while the lowest were in house \#5 (outdoor $360 \mu \mathrm{g} \cdot \mathrm{m}^{-3}$ and indoor $248 \mu \mathrm{g} \cdot \mathrm{m}^{-3}$ ). The I/O ratio for this event was 0.76 
on average. The $\mathrm{I} / \mathrm{O}$ ratio values for these storms are calculated as an average for several houses. The values $(0.74-0.79)$ are somewhat higher than the I/O ratio values $(0.58-0.68)$ calculated for two other dust storms (medium and high levels - see Figure 3), but in a single house. In all cases (Figures 3 and 6) the I/O ratio was below 1 , which is significantly different from the background conditions and low intensity storms $(>1)$. Nonetheless, the results of the $\mathrm{I} / \mathrm{O}$ ratio demonstrate the variability in the impact of dust storms on the indoor PM concentrations.

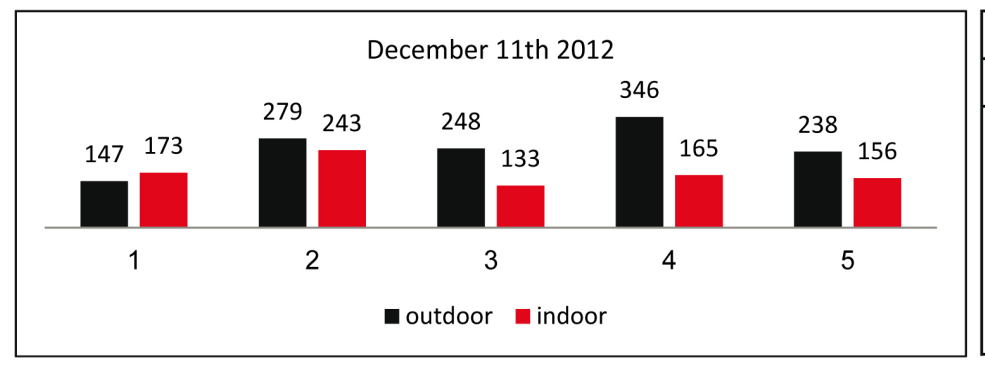

\begin{tabular}{|ccccccc|}
\hline \multicolumn{3}{|c}{ Outdoor } & \multicolumn{3}{c|}{ Indoor } \\
\hline House & $\min$ & $\max$ & $\operatorname{mean}$ & $\min$ & $\max$ & mean \\
\hline 1 & 78 & 401 & 147 & 105 & 518 & 173 \\
2 & 186 & 389 & 279 & 136 & 513 & 243 \\
3 & 153 & 474 & 248 & 81 & 218 & 133 \\
4 & 213 & 471 & 346 & 116 & 214 & 165 \\
5 & 175 & 381 & 238 & 83 & 223 & 156 \\
\hline
\end{tabular}

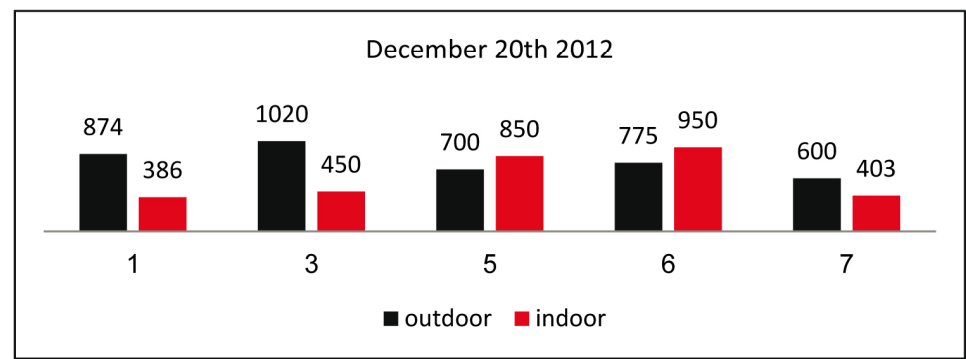

\begin{tabular}{|ccccccc|}
\hline \multicolumn{3}{|c}{ Outdoor } & \multicolumn{3}{c|}{ Indoor } \\
\hline House & $\min$ & $\max$ & mean & $\min$ & $\max$ & mean \\
\hline 1 & 289 & 1330 & 874 & 286 & 531 & 386 \\
3 & 816 & 1450 & 1020 & 371 & 680 & 450 \\
5 & 278 & 737 & 700 & 654 & 1340 & 850 \\
6 & 572 & 1020 & 775 & 755 & 1170 & 950 \\
7 & 129 & 389 & 600 & 262 & 1240 & 403 \\
\hline
\end{tabular}

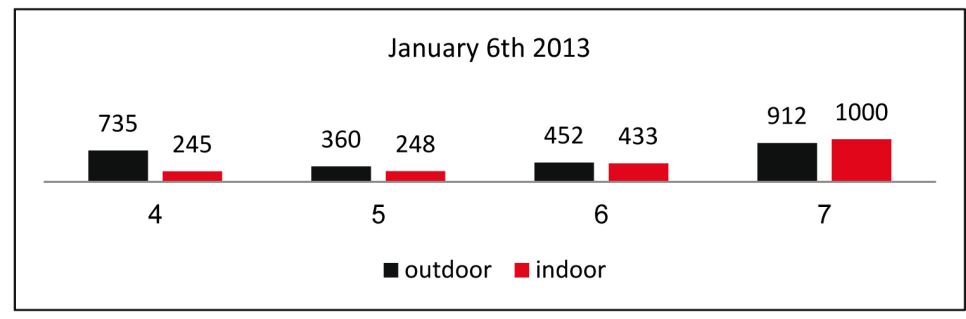

\begin{tabular}{|ccccccc|}
\hline \multicolumn{4}{|c}{ Outdoor } & \multicolumn{3}{c|}{ Indoor } \\
\hline House & $\min$ & $\max$ & $\operatorname{mean}$ & $\min$ & $\max$ & mean \\
\hline 4 & 405 & 1690 & 735 & 154 & 371 & 245 \\
5 & 246 & 530 & 360 & 188 & 305 & 248 \\
6 & 238 & 1540 & 452 & 185 & 1820 & 433 \\
7 & 430 & 1830 & 912 & 511 & 1510 & 1000 \\
\hline
\end{tabular}

Figure 6. Average $\mathrm{PM}_{10}$ concentrations (values in $\mu \mathrm{g} \cdot \mathrm{m}^{-3}$ are presented above the columns) for indoor (red) and outdoor (black) of houses in the study area (Figure 4) during different dust events. Summary statistics is also presented on the right.

\section{Conclusions}

The results show that the atmospheric $\mathrm{PM}_{10}$ concentrations in an arid city can increase significantly from 20 to $120 \mu \mathrm{g} \cdot \mathrm{m}^{-3}$ on non-dust days to more than $1500 \mu \mathrm{g} \cdot \mathrm{m}^{-3}$ during dust events. The high atmospheric (outdoor) dust concentrations have a direct effect on the indoor environment of houses. The indoor concentrations reached values as high as $1000 \mu \mathrm{g} \cdot \mathrm{m}^{-3}$, which is significantly higher than the air quality guidelines.

The time lag in the increased indoor concentrations due to dust events varies between storms from several minutes to about one hour. Both indoor and outdoor concentrations varied considerably, depending on the dust storm intensity. The calculated indoor/outdoor $(\mathrm{I} / \mathrm{O})$ ratio was $\mathrm{I} / \mathrm{O}<1$ for all measured houses in this study during a dust event. It ranged from 0.79 for low-level storms to 0.58 during the strongest storms. 
Variations of outdoor and indoor PM concentrations during dust storms were demonstrated. Considering the indoor environment, no evidence was found for the impact of the house location in the city. The most important factors that were found to control the PM concentrations were: the dust storm intensity (low, medium, high), duration (and time lag), and physical characteristics of the houses.

This work is part of a comprehensive study aiming to explore the dynamics of dust storms in the city scale, and to examine the effect of natural PM on exposure risk for human health. The findings indicate that during dust events people are exposed to high levels of PM concentrations in indoor and well as outdoor environments. Such information is critical for assessment of policy interventions to reduce adverse health effects, especially in arid and semi-arid regions that are strongly associated with dust storms due to their proximity to dust sources.

\section{Acknowledgments}

The research was supported by a grant from the Environment and Health Fund (No. RGA1004).

\section{Author Contributions}

Helena Kransov, Itzhak Katra and Michael Friger conceived and designed the experiments; Itzhak Katra led the experiments; Helena Kransov collected and analyzed the data; Michael Friger contributed statistical analysis tools; Helena Kransov wrote the paper.

\section{Conflicts of Interest}

The authors declare no conflict of interest.

\section{References}

1. Katra, I.; Arotsker, L.; Krasnov, H.; Zaritski, A.; Kushmaro, A.; Ben-Dov, A. Richness and Diversity in Dust Storm borne Biomes at the Southeast Mediterranean. Sci. Rep. 2014, 4, 5265.

2. Mitsakou, C.; Kallos, G.; Papantoniou, N.; Spyrou, C.; Solomos S.; Astitha, M.; Housiadas, C. Saharan dust 15 levels in Greece and received inhalation doses. Atmos. Chem. Phys. 2008, 8, 7181-7192.

3. Querol, X.; Pey, J.; Pandolfi, M.; Alastuey, A.; Cusack, M.; Perez, N.; Moreno, T.; Viana, M.; Mihalopoulos, N.; Kallos, G.; Kleanthous, S. African dust contributions to mean ambient PM10 mass-levels across the Mediterranean Basin. Atmos. Environ. 2009, 43, 4266-4277.

4. Krasnov, H.; Katra, I.; Koutrakis, P.; Friger, M.D. Contribution of dust storms to PM10 levels in an urban arid environment. J. Air Waste Manag. Assoc. 2014, 64, 89-94.

5. Neophytou, A.M.; Yiallouros, P.; Coull, B.A.; Kleanthous, S.; Pavlou, P.; Pashiardis, S.; Dockery, D.W.; Koutrakis, P.; Laden, F. Particulate matter concentrations during desert dust outbreaks and daily mortality in Nicosia, Cyprus. J. Expo. Sci. Environ. Epidemiol. 2013, 23, 275-280.

6. Yitshak Sade, M.; Novack, V.; Katra, I.; Gorodischer, R.; Tal, A.; Novack, L. Non-anthropogenic dust exposure and asthma medications purchase in children. Eur. Respir. J. 2014, 45, 652-660. 
7. Vodonos, A.; Friger, M.; Katra, I.; Avnon, L.; Krasnov, H.; Koutrakis, P.; Scwartz, J.; Lior, O.; Novack, V. The impact of desert dust exposure on hospitalization due to the exacerbation of chronic obstructive pulmonary disease. Air Qual. Atmos. Health 2014, 7, 433-439.

8. Pérez, L.; Tobias, A.; Querol, X.; Künzli, N.; Pey, J.; Alastuey, A.; Viana, M.; Valero, N.; González-Cabré, M.; Sunyer, J. Coarse Particles from Saharan Dust and Daily Mortality. Epidemiology 2008, 19, 800-807.

9. Middleton, N; Yiallouros, P.; Kleanthous, S.; Kolokotroni, O.; Schwartz, J.; Dockery, D.W.; Demokritou, P.; Koutrakis, P. A 10-year time-series analysis of respiratory and cardiovascular morbidity in Nicosia, Cyprus: The effect of short-term changes in air pollution and dust storms. Environ. Health 2008, 7, 39.

10. Thornburg, J.; Ensor, D.S.; Rodes, C.E.; Lawless, P.A.; Sparks, L.E.; Mosley, R.B. Penetration of particles into buildings and associated physical factors. Part I: Model development and computer simulations. Aerosol Sci. Technol. 2001, 34, 284-296.

11. Chen, C.; Zhao, B. Review of relationship between indoor and outdoor particles: I/O ratio, infiltration factor and penetration factor. Atmos. Environ. 2011, 45, 275-288.

12. Long, C.M.; Suh, H.H.; Catalano, P.J.; Koutrakis, P. Using time- and size-resolved particulate data to quantify indoor penetration and deposition behavior. Environ. Sci. Technol. 2001, 35, 2089-2099.

13. Krasnov, H.; Katra, I.; Novack, V.; Vodonos, A.; Friger, M.D. Increased indoor PM concentrations controlled by atmospheric dust events and urban factors. Build. Environ. 2015, 87, 169-176.

14. Prospero, J.M.; Ginoux, P.; Torres, O.; Nicholson, S.E.; Gill, T.E. Environmental characterization of global sources of atmospheric soil dust identified with the Nimbus 7 Total Ozone Mapping Spectrometer (TOMS) absorbing aerosol product. Rev. Geophys. 2002, 40, 2-1-2-31.

15. Ganor, E.; Osetinsky, I.; Stupp, A.; Alpert, P. Increasing trend of African dust, over 49 years, in the eastern Mediterranean. J. Geophys. Res. 2010, 115, 1-7.

16. Jayaratne, E.R.; Johnson, G.R.; McGarry, P.; Cheung, H.C.; Morawska, L. Characteristics of airborne ultrafine coarse particles during the Australian dust storm of 23 September 2009. Atmos. Environ. 2011, 45, 3996-4001.

17. Ramachandran, G.; Adgate, J.L.; Pratt, G.C.; Sexton, K. Characterizing indoor and outdoor 15-minute average PM2.5 concentrations in urban neighborhoods. Aerosol Sci. Technol. 2003, 37, $33-45$.

18. Heal, M.R.; Beverland, I.J.; McCabe, M.; Hepburn, W.; Agius, R.M. Intercomparison of Five PM10 Monitoring Devices and the Implications for Exposure Measurement in Epidemiological Research. J. Environ. Monit. 2000, 2, 455-461

19. Levy, J.I.; Houseman, E.A.; Spengler, J.D.; Loh, P.; Ryan, L. Fine particulate matter and polycyclic aromatic hydrocarbon concentration patterns in Roxbury, Massachusetts: A community-based GIS analysis. Environ. Health Perspect. 2011, 109, 341-347.

20. Yanosky, J.D.; Williams, P.L.; MacIntosh, D.L. A comparison of two directreading aerosol monitors with the federal reference method for $\mathrm{PM}_{2.5}$ in indoor air. Atmos. Environ. 2002, 36, $107-113$. 
21. Kingham, S.; Durand, M.; Aberkane, T.; Harrison, J.; Wilson, J.G.; Epton, M. Winter Comparison of TEOM, MiniVol and DustTrak PM10 monitors in a Woodsmoke Environment. Atmos. Environ. 2006, 40, 338-347.

22. McNamara, M.L.; Noonan, C.W.; Ward, T.J. Correction factor for continuous monitoring of wood smoke fine particulate matter. Aerosol Air Qual. Res. 2011, 11, 315-322.

23. Zhao, L.; Chen, C.; Wang, P.; Chen, Z.; Cao, S.; Wang, Q.; Xie, G.; Wan, Y.; Wang, Y.; Lu, B. Influence of atmospheric fine particulate matter $\left(\mathrm{PM}_{2.5}\right)$ pollution on indoor environment during winter in Beijing. Build. Environ. 2015, 87, 283-291.

(C) 2015 by the authors; licensee MDPI, Basel, Switzerland. This article is an open access article distributed under the terms and conditions of the Creative Commons Attribution license (http://creativecommons.org/licenses/by/4.0/). 